\title{
CONSELHOS DE HYGIENE SEXUAL E MORAL
}

\author{
Por Pedro de Alcantara
}

\section{O OBJECTIVO DESTE FOLHETO}

Estes conselhos correpondem a uma grande necessidade, necessidade que não é de hoje, mas đe todos os tempos. Destinam-se elles a dar aos rapazes os corhecimentos das cousas da vida sexual ne. cessarios e sufficientes para que elles nāo sejam apanhados de surpreza, por uma dessas aventuras que o vulgo chama "de rapaz" e que por sua ignorancia pode ser des mais funestas consequencias.

E' uma triste realidade, mas é uma realidade, que o rapaz chegando á edade em que seu instincto sexual se desperta encontra-se absolutamente ignorante de tudo que lhe pode interessar em phase tão delicada de sua vida e, o que é ainda peior, vê fechadas todas as fontes legitimas por onde poderia ser instruido. Com effeito, ceus paes, seus profescores, seus superiores, emfim, fazem o firme proposito de nem sequer fallar de taes assumptos em sua presença crendo respeitar assim um pudor que elles acham natural, mas năo vendo que com isso se tornam responsaveis pelos desfortunios que o rapaz, inexperiente, procura para si mesmo. As consequencias aesse mal comprehendido amôr dos Paes por seus filhos são as mais desastrosas, como se verá adeante, mas nem assim se resolve quebrar esse silencio verdadeiramente criminoso. Foi por isso que surgio a idéa desta publicação, em que os rapazes encontrassem, expostos em linguagem ao seu alcance, os esclarecimentos de que secessitam para ficar com seu espirito em condições de reagir contra os maus impulsos que partem de dentro de si proprios e de tudo que os cerca. Terão assim os rapazes informações mais sinceras. mais puras, mais scientificas do que as que são dadas por companheiros desvirtuados e corruptos que outra coisa não fazem senão envenenar para todo o sempre a vida dos rapazes incautos que lhes caem nas garras. Os numerosos livros que existem escriptos sobre o problema sexual de nenhum modo satísfazem ao objectivo visado por este pequeno trabalho pois ou são de preço elevado, ou escrirtos em linguagem acima do alcance de quem não lida com taes assumptos ou então demasiadamente extensos, pelo que o rapaz desiste de lel-os e apprehendel-os.

\section{UM POUCO DE ANATOMIA E DE PHYSIOLOGIA}

A falta de conhecimentos sobre a anatomia e a physiologia dos orgãos sexuaes, isto é, do apparelho genital, é um defeito gravissimo da educação dos rapazes, que em geral fazem delles as idéas mais absurdas.

Anatomia é forma e physiologia é funcção. Sem conhecer a forma e o funocionamento dos orgãos sexuaes é muito difficil ao rapaz 
comprehender os perigos das molestias venereas, e outro não nosso intuito.

Eis porque resolvemos expôr aqui, de modo succinto, algumas noçóes de anatomia e physiologia dos orgãos sexuaes, para que se desvaneçam do espirito dos leitores as idéas creadas pelas descripções dos companheiros, cada qual mais absurda e tola. Estenderemos de leve taes noções ao apparelho urinario, que está intimamente li gado ao apperelho genital, formando ambos, em conjuncto, o apparelho genito-urinario. Este apparelho é formado de tres partes, uma propria ao genital, uma ao urinario e outra commum a ambos. A parte propria ao apparelho urinario é formada primeiramente dos dois rins, que estão collocados nas costas, na altura da cintura ou um pouco acima, um ao lado do outro $\theta$ ambos do lado da espinha. São os orgãos que produzem a urina, e têm a forma de um grão de feijão, mas com mais ou menos oito centimetros de comprimento. Os rins produzem continuamente a urina e por meio de dois canaes chamados uretéres e enviem-na para a bexiga, situada muito mais abaixo, e que se destina a accumular a urina até a occasião da micção. A urina sae da bexiga por um canal chamado urethra, que já é commum com o apparelho genital. A parte propria do apparelho genita) compõe-se tambem de orgãos productores, orgãos conductores e orgãos accumuladores de esperma. Os principaes orgãos produ. ctores sãos os testiculos, situados dentro do escroto, na frente do abdomen, entre os đois membros inferiores. São formados por uma multidão de finos canaes que se reunem para formar o canal epididymario. Além dos testiculos, ha einda algumas glandulas, que são a prostata, as glandulas de Cooper e as de Littre, situadas ao longo dos canaes conductores de esperma. Estes canaes são o canal epididymario, de que já fallámos, e o canal deferente, que corresponde aos uretéres. Os orgãos em que o esperma se accumula são as vesiculas seminaes, correspondentes á bexiga e situadas ao lado desta. Das vesiculas seminaes saem dois canaes, chamados ejaculadores, que atravessam a prostata, situada em baixo da bexiga, indo ter á urethra, que, por sua vez, tambem atravessa a prostata.

Vê-se, pois, que os canaes ejaculadores desembocam na urethra, logo depois que esta sae da bexiga, e dahi por deante temos a parte commum aos dois apparelhos urinario e genital. Esta parte é a urethra, que se dirige para fóra do organismo, estando, na porção terminal, contida dentro do penis, orgão do acto sexual, cuja ponta se ehama glande. $O$ penis é formado por um corpo cheio de orificios que se communicam entre si $\theta$ em cujo centro passa a urethra.

Estes detalhes seccos e aridos tomarão viđa quando se fallar do seu funccionamento.

O funccionamento do apparelho urinario quasi já está con'hesido dos leitores: a urina produzida nos rins desce pelos uretéres $\theta$ se accumula na bexiga até o momento da micção. 0 funccionamento do apparelho genital é muito semelhante. Os testiculos produzem os espermatozoides, que vão fecundar o ovulo feminino. Esses, os espermatozoides, seguindo o caminho já descripto, vão ás vesiculas seminaes, cujas contracções, no acto sexual, os enviam para a urethra, por onde são levados aos orgãos genitaes femininos. 0 papel das glandulas de Cooper de Littre e de prostata é produzir em um liquido que vae diluir o producto dos testicu'os. 0 producto de todas essas glandulas, inclusive o dos testiculos, chama-se esperma. 0 
acto sexual se faz á custa da erecção do penis, o que se realiza pelo affluxo de sangue ao membro, enchendo os orificios que existem no вEu interior e que se chamam corpos esponjosos, pela semelhanca que apresentam com a estructura da esponja.

\section{COMPATIBILDADE DA CONTINENCIA SEXUAL COM A SAGDE}

De posse os leitores desse substractum anatomico e physiologico dos orgãos de reproducção, facil lhes fica comprehenderem tudo quanto a respeito thes dissermos. Propondo-nos agora a mostrar a compatibilidade da continencia sexual com a saúde, procuraremos responder a todas as accusaões que em tal sentido fazem os adversarios da abstinencia sexual. Isto é muito importante, pois muito rapez ha por ahi que deseja manter-se puro e não o faz porque seus companheiros, perversos ou inconscientes, the enchem a cabeça com caraminholas de toda a especie a respeito das consequencias da cortinencia sexual.

A primeira objecção é que sendo o instincto sexual uma necess1ade como o somno, o individuo que não o satisfaça prejudica-se tanto quanto aquelle que não dorme. Isto é uma bobagem sem nome, e a prova é que se o instincto sexual por sua imperiosidade se assemelhasse ao somno, não haveria abstemios sexuaes, pois não os ha do somno. E, no emtanto, numerosos são os rapazes que, animados por um nobre ideal ou esclarecidos por uma educação conveniente, sabem trazer seu corpo sob o jugo impertubavel da razão, que não os deixa afastarem-se uma linha do caminho traçado. Taes rapazes são mais numerosos do que á primeira vista se suppõe; nào apparecem porque se acanham em confessar uma situação que, vẹo contrario, só os pode honrar. e não são comprehendidos porque o meio em que vivem é pouco esclarecido.

uma cousa que confundiria os detractores da castidade mascuiina é que taes rapazes, que souberam se dominar, não são os uitimos nos estudos nem no trabalho, antes brilham como os que mais o fazem. No corpo e no espirito desses rapazes não ha uma molestia ou uma mancha qualquer; pelo contrario, são uma garantia de que irão constituir uma familia sã, com fihos sadios e fortes, que bemdirão os que the deram essa saúde. Isso é que os adversarios da castidade masculina não querem vêr. Muitos o fazem por maldede, para procurar companheiros para os males que os affligem e que elles foram buscar nas relações illicitas que mantiveram. A èsses não se deve resposta, pois elles não a merecem, senão o mais profundo desprezo. Outros, entretanto, o fazem sinceramente julgando praticar um beneficio, $\theta$ a esses deve-se esclarecer o espiríto, não só para que elles não vão levar a confusão a outrem, como para que procurem se dominar e pôr um termo a uma vida que só os pode prejudicar. A resposta é muito simples. Dizem taes pessoas que o instincto sexual precisa ser satisfeito, porque nos antmaes, em que a vida sexual deve ser a mais natural possivel, não se vê abstinencia nenhuma.

Ora, a questão que nos occupa não pode ser posta neste pé; a equiparacão dos homens' aos animaes nã̃o deve ser admittida assim com tanta facilidade, pois as condições de cada um não são identicas. Em primeiro logar, os animaes têm o cio, isto é, espaços pe- 
riodicos de tempo em que suas funcções genesicas se exhaltam, ao passo que os homens têm a faculdade da escolha do tempo em que hão de praticar o acto sexual.

E não é só. Os animaes como animaes que são, desconhecem todas es conveniencias de ordem social e moral. Não constituindo famiia, como ainda não constituem certas raças humanas inferiores, não se organisanđo em sociedade, elles não têm no acto sexual outro instincto que o da simples reproducção numerica; no homem, ha conveniencias de toda ordem, incompativeis com a vida sexual como a praticam os aniniaes.

Se taes conveniencias não existissem, o cuidado de organisar uma familia, a preoccupação de que os filhos sejam gerados nas melhores condições materiaes e moraes, a vantagem de viver em sociedade, se taes conveniencias não existissem, repetimos, os homens não seriam homers, mas sim animaes.

Não se pode impunemente separar no homem os dois elementos animal e racional, o primeiro para viver sexualmente, o segundo para viver mentalmente. O elemento racional, justamente porque é racional, ha de influir sobre o outro, ditando-lhe a conducta mais compativel com seu melhor destino.

A se estabelecer uma tal equiparação dê-se ao homem a promiscuidade existente entre os animaes, e era uma vez civilisação, progresso. sociedade, moral, e outras conquistas da humanidade.

Estabelecido, assim, esse principio de ordem geral, vejamos algumas das objecçõè feitas á abstinencia sexual pre-matrimonial.

Primeiramente a supposição de que não se pode fugir á satisfacção de um tão imperioso desejo.

E' falso. A necessidade sexual está em relação com o estado de espirito do individuo. Tudo prova que um espirito que se domina, domina tambem seu instincto sexual. Todo rapaz, por mais desregrada que seja sua vida sexual, ao ficar noivo modera sues actividades sexuaes, quando não as cessa de todo. E' a influencia santificadora da noiva, que se exerce tão beneficamente. Onde está a "necessidade" sexual?

Desde que o espirito do rapaz ache um ponto de apoio moral no caso, a noiva - a tal necessidade desapparece como que por encanto. Se assim é, porque não dar ao rapaz, desde que elle se desperta sexualmente, pontos de apoio, como a consciencia do papel a representar na sociedade, a ambição de constituir uma familia de que nasçam filhos fortes e sadios, que agradeçam aos Paes a saúde que lhes deram, a noção precisa da ameaça que a liberdade sexual ccnstitúe para seus melhores 6onhos pelos males physicos que acarreta, a consciencia de que a incontinencia sexual aberra de tudo que a hygiene, a medicina, a sociedađe, a religião, a moral aconse. lham e ordenam?

A abstinencia sexual, quando livremente desejade pelo rapaz, é de todo possivel, e após certo tempo de lucta, facil.

Não o é para aquelles que, simplesmente por medo das molestias, fogem aos actos sexuaes cuja reprezentação palpita em seu espirito: ebstinencia sexual physica sem abstinencia sexual do espirito é um absurdo, e, o que é mais, uma utopia. Não é essa a ebstinencia que aconselhamos. 
Dizem mais, os que reprovam a abstinencia sexual, que ella atrophia os orgãos sexuees. Ha aqui duas ordens de considerações por se fazer.

Primeiro, que abstinencia sexual não é inercia sexual pois os testiculos continuam a produzir o esperma, que é eliminado pelo organismo. Depois, ha alguns exemplos que queriamos ver explicados pelos nossos antagonistas: A mulher que tem seu primeiro filho aus trinta annos, por exemplo, amamenta-o como se o tivesse tido acs dezoito: onde foi a atrophia das glandulas mamarias, que estiveram tanto tempo em repouso?

E não é só: um indiviđuo que passe mezes ou annos sem chorar, nem por isso deixará de produzir lagrimas, quando para isso apparecer opportunidade e occasião; as glandulas lacrimaes não se atrophiaram.

A' falta desse argumento, dizem que a abstinencia sexual determina um estado de excitação, pondo o individuo em um permanente estado de desejo insatisfeito. $\mathrm{Ha}$ pouco era a atrophia, agora é a excitação. Estaria muito đireito, se o rapaz não fizesse a hygiene do espirito. Desde que esta se faça, completa e integral, não haverá excitação, pois faltará o estimulo que vem do espirito e que e o mais forte.

Outros, mais francos, dizem que a actividade sexual pre-matrimonial ou mesmo extra-matrimonial (!) nada mais é que a satisfacção natural de um legitimo desejo. Isto é berrante de injustiça e inconsciencia.

Preliminarmente se dirá que o desejo é muito relativo, e que se devemos dar aos nossos desejos satisfacão immediata nenhum mal haverá em ser-se abstinente desde que se queira sel-o. Mas não é isso só. Se erigirmos o prazer em norma de vida, onde vae parar o mundo? Cada satisfação é comprada com o sacrificio de uma renuncia. Uma sociedade cujos membros dessem larga satisfacção aos seus desejos estaria irremissivelmente perdida.

Satisfaçam-se os desejos legitimos. O da pratica sexual não o é. Se o fosse, seria tambem para a mulher. E qual desses individuos quereria para suas filhas uma conducta egual a que elle adoptou para si, e que elle defende?

De posse destes conhecimentos geraes, 1sto $\dot{e}$, que o instincto se. xual só se torna uma necessidade quando o espirito o quer, que a continencia sexual não é incompativel com a saúde e com o bom funocionamento dos orgãos sexuaes, que a incontinencia sexual é in. Justa, amoral, anti-hygienica e anti-social, facil será, a quem quizer, responder ás objecçōes feitas contra a abstinencia sexual pre-matrimonial. Se para algumas objecções faltarem respostas, procure-se uma pessôa mais illustrada, procure-se um medico amigo, e ver-se-á a que a poeira se reduzirão essas objecções, filhas umas vezes da maldade. outras da ignorancia.

\section{MALES VENEREOS}

Vista, assim, a compatibilidade da continencia sexual com a saude, passaremos a ver os males causados pela incontinencia sexual, isto 6. pela pratica do acto sexual antes da epoca marcada pela Natureza e pela Moral, o casamento. Os rapazes que leram as noções de anatomia e phyisiologia dos orgãos sexuaes estão bem em condições d• 
nos comprehender e bem alcançar a importancia que os males venereos têm em relação á saúde do individuo. Sim, porque os adversarios da castidade masculina, esforçando-se para attribuir a esta uina grande serie de molestias, esquecem-se dos gravissimos e desastrosos resultados da pratica sexual antes do casamento. Como se verá adiante, as molesties cujo contagio e transmissão correm quasi exclusivamente por conta do acto sexual impuro são das mais terriveis, pelas consequencias directa $\theta$ remotas.

Dos males venereos, o mais commum e tambem, se não fôr con-

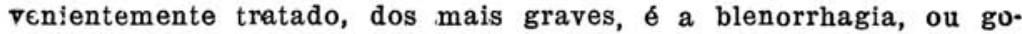
norrhéa, ou esquentamento, o qua já foi chamado "a grande chaga di nossa mocidade". Antigamente, quando seus perigos eram desconhecidos, consideravam-na um timbre de virilidade (!). Hoje é tida como uma calamidade inđividual e social que cumpre a todo eusto combater. Consiste no corrimento de puz pela urethra, puz esse que contém o microbio da molestia, que é o gonoccocco e que pode causar uma blenorrhagia em qualquer mucosa com que seja posto em contacto. Causa dores, difficuldađe á miç̧ão, por causa da inflammação da urethra por onde sáe a urina. Bem tratada, geralmente sára. Mas se o tratamento tarda ou é pouco rigoroso, temos a blenorrhagia chronica, que passando, ás vezes, desappercebida, fiç no individuo como um fóco de infecção perigosissimo. Mesmo quando não é chronica é muito perigosa, pois pode caminhar e attir.gir orgãos muito importantes. Seguindo ao inverso o caminho percorrido pelo esperma vae á prostata, ao canal epididymario, aos testiculos, provocando soffrimentos grandes. Ou, chegando á bexiga, provoca difficuldades na micção e outros incommodos e paśando aos rins pode infeccionar o sangue, o que dá em consequencia a produccão de affecções do coração e rheumatismo.

O segundo mal, por ordem de frequencia, é a syphilis. Pode ser apanhada por uma multiđão de maneiras, por um simples beijo, pelo emprego de objectos infeccionados (louça, talher, navalha, lapis, Instrumentos de musica, etc.) ou pelo uso de roupas contaminadas. Mas o principal meio de transmissão, o responsavel por noventa e nove contagios em cem, é o acto sexual impuro. A syphilis foi comparada a um drama em tres actos. O primeiro é a infecção do individuo pela penetração do microbio da syphilis, a "spirocheta pallida" ou "treponema pallido", no organismo por um esfolado ou uma irritação du pelle. Forma-se então o cancro duro, que mesmo quando sára pode infeccionar o individuo. Este periodo chama-se syphilis primaria. O cancro duro quasi semipre se localisa na glande, pois, como já ficou dito, o maior numero de infecções corre por conta do acto sexual com uma perssoa doente. O segundo acto é a syphilis secundaria, que se manifesta pelas dôres de cabeça muito fortes, anemia e muitas manifestações generalisadas na pelle. Localisa-se tambem na mucosa da bocca $\Theta$ da garganta. (placas mucosas), constiuindo Isso um terrivel perigo por causa da transmissão, que então se torna facilima. O terceiro acto do drama constitue a syphillis terciaria, em que o microbio, tendo escolhido a sua habitação, solapa a vitalidade de um ou de varios orgãos; e temos então manifestações no coracão, na aorta (grande arteria que sae do coração), nos pulmões, na lingua, no nariz, no figado, no systema nervoso (dando a terrivel paralysia geral) e em quasi todos os orgãos. Nós, por nossa conta, ajurtamos a esse drama um epilogo tragico, a morte do individuo no meio dos mais cruciantes padecimentos physicos, mas tambem 
moraes, por reconhecer que tanto soffrer poderia ter sido evitado se tivesse sabido se conter num momento de desvario.

o terceiro mal, pela frequencia. é o cancro molle, que geralmente se localisa no ponto em que o microbio penetrou na pelle. E' causado por um microbio chamado bacillo de Ducrey. E' contagioso $\theta$ pode ser acompanhado de complicações como producção de ingua nas virilhas e tambem o phagedenismo, o que quer dizer a extensão do cancro molle pelas partes vizinhas, podendo invadir grandes porções do corpo.

Ahi ficam, pois, conhecimentos elementares sobre os males venereos, para que o rapaz que se entregue á vida sexual precoce saiba - que fatalmente o espera, mais cedo ou mais tarde.

Mas o que dissémos refere-se apenas aos riscos individuaes dessas molestias; diremos agora elgumas palavras acerca dos perigos sociaes, ñ̃o menos graves. Antes de mais nada, diremos que um individuo infectado constitue um fóco perigoso de contagio, e isto é um perigo para a sociedade, cujos membros são assim expostos. A sociedade é tambem prejudicada pelos males causados na propria familia do individuo doente. Assim, um individuo blenorrhagico pode infeccionar a esposa, que, creada num meio de pureza, vem apanhar tão repellente molestia daquelle a quem ella entregou seu futuro. A blenorrhagia na mulher pode lhe acarretar a esterilidade, isto é, a incapacidađe de ter fillhos. E não é só. Se uma mulher está infeccionada pelo gonocco no momento de dar á luz um filho, é quasi certo qus esse filho infeccione os seus olhos e então correrá o risco de ficar cego. Antes de se conhecerem os antisepticos e os desinfectantes, dois terços dos cegos deviam sua desgraça ao gonococco.

A syphilis é egualmente transmittida de pae para filho atravez da esposa, e actua maleficamente sobre algumas gerações. O capitulo da syphiis congenita é cheio de tristezas, de dores, de esperanças cortadas, tal o numero de crianças que morrem de syphilis. A 'iás, a morte de uma creança syphilitica é um bem, pois se ella viesse a crescer seria um ente infeliz $\theta$ desgraçado pelos males que traria do berço.

Vê-se, pois, como é descabido o individuo atirar-se á vida sexual pura fugir áquelles pretensos males causados pela continencia, quan. do es molestias realmente causadas pela incontinencia são muitissimo mais graves não somente para o individuo como egualmente pra a sociedade. E' o mesmo que o individuo se suicidar para nảo correr o risco de apanhar um constipado.

(Continúa)

Attesto que tenho empregado em minha clinica o VIDAN com excellentes resultados.

DR. RUBIÃO MEIRA 